\title{
HIGH SCALE 3D MODELLING AND ORTHOPHOTO OF CURVED MASONRIES FOR A MULTIPURPOSE REPRESENTATION, ANALYSIS AND ASSESSMENT
}

\author{
G. Sammartano, A. Spanò \\ Politecnico di Torino, DAD, 10129, Torino, Italy - (giulia.sammartano, antonia.spano)@ polito.it
}

Commission WG V/1, WG V/2, WG II/8 WG IV/2

\begin{abstract}
KEY WORDS: 3D photogrammetry, Cultural Heritage documentation, vertical structures, orthoimage, surface development, deterioration, pathologies mapping
\end{abstract}

\begin{abstract}
:
It is important nowadays to underline some relevant topics concerning the effective contribution of 3D high detailed products derived from innovation and integration of Geomatics technologies, allowing a remarkable development in descriptive metric capabilities, supporting and improving the material recording, representation, analysis and characterization about alteration of the constructive systems. Considering the relevance of the complex interdisciplinary research of these issues that move around the Cultural Heritage safeguard and due to its extreme vulnerability, these models must give a response to different problems. Primarily they has to provide complete models on which to pursue accurate morpho-dimensional documentation, and to base structural assessment, decay investigations, and consequently to underpin restoration practices and support operational workflow in $\mathrm{CH}$ assets monitoring. Some peculiarities of new methods for semiautomatic processing algorithms are thus evidenced, advantaging their proficiency to behave as tools for a more sustainable approach in the general process of preservation and protection. Specifically about the ancient masonries documentation, the chance of using digital products derived from very high scale models, as the detailed orthoimages projection and surfaces development offers many opportunities. Here, a late-medieval stratified dovecote tower in Verolengo (TO) with a particular trunk-conical shape had been analysed in order to reconstruct an identity and a historical and architectural framework, de facto not recognized yet. A 3D reconstruction by dense matching techniques will be presented, in the complex context that are the vertical high buildings, presenting one of the highest level of vulnerability. The importance of the 3D model availability, closely connected to dense radiometric information, has been particularly expressed in two main direction for the diagnosis both of volumetric structure assessment and the material characterization of the mixed masonries walls.
\end{abstract}

\section{INTRODUCTION}

We have witnessed in recent years to a continuous innovation and integration of Geomatics technologies, as LiDAR range-based sensors and close-range photogrammetry image-based approaches, in their applications to Cultural Heritage recording and representation, considering the relevance of interdisciplinary research and the complexity of the issues that move around the Heritage safeguard and due to its extreme vulnerability. In fact, some 3D measurement techniques and image based survey have been developed in order to enhance proper documentation of Cultural Heritage based on multi-disciplinary requirements, different users' needs and various detail levels: from the territorial and urban scale to that of the building, up to the largest scale, necessary for a correct report of the single architectural elements and structural systems. (Apollonio et al., 2017; Ortiz-Cordero \& Hidalgo Fernández, 2017; Voulodimos et al., 2016; Bastonero et al., 2014; Lerma et al., 2011)

In this respect, the national legislation framework with the ministerial directive for the assessment and mitigation of seismic risk regarding the protected Cultural Heritage debate about provisions concerning the recording and the representation of the crack pattern and all other possible injuries or alterations to the traditional masonry. They must allow the identification of the causes and possible evolution of structural issues (Chiabrando et al., 2017). These topics can be met by methods that allow the measurements of shapes in the space (to detect misalignments, bulging, out-of-plumb, subsidence, depressions in the vaults, soils and ceilings) and high detailed textures, applicable through photogrammetric systems, both to flat surfaces and double curvature surfaces (Bevilacqua et al., 2016; Spano \& Vizzini, 2016).

Here a test-case was considered since its particular vertical building, subjected to specific structural stresses. A rural tower with a trunk-conical shape with a dovecote volume as recent superelevation, will be presented with the aim to experiment the behaviour of the innovative dense matching techniques by closerange photogrammetry in a critical framework, which are the vertical high buildings, from a terrestrial point of view. Some existing algorithms and available commercial and open-source software will be presented to offer a valuable hands-on tool as several traditional 2D graphical vectorialization and other 3D advanced digital products; they can be computed as useful support for varied expertise approaches in the framework of decay assessment and material restoration. It will be then displayed some important aspects related specifically to the potentialities offered by the images orthoprojection and interpretation too, thanks to the strict link between vector model and RGB raster data; through the performance of geometric projection and development of orthoimages from a curved surface, the trunk-conical volume of the tower can be read on an unrolled surface that approximates it. On this product metrically controlled it is possible to analyse and map by plotting vectorial representations, any architectonical element, structural alteration and material deterioration.

\section{VULNERABILITY OF VERTICAL STRUCTURES AND RESPONSE OF GEOMATIC METHODS}

The widespread Italian built heritage, as well as that of many other countries, is strongly characterized by the presence of historical vertical structures, essentially due to towers and bell towers. After a first application of the Directive of 12/10/2007 (G.U.N ${ }^{\circ} 24$ of 29/01/08), operational protocols for assessing and reducing the seismic risk of towers, numerous studies have been undertaken aiming at analysing these types of highly vulnerable architectural assets, in relation to the seismic classification of the territory laid down by that directive, which contributed to the updating of the DPCM Directive 2011. Further updates can be found in the adoption of the datasheet (SCHEDA) for the damage to cultural heritage - churches model A-DC (2011), which contains the bell 
tower subsection, as well as the monumental buildings datasheet $\mathrm{B}$ - DP (2006). Both the directive and the damage detection Datasheet have a similar approach in prioritizing targeted strategies not so much in defining a high level of risk or damage as well as recognizing phenomena with homogeneity characteristics over the sample and by standardized procedures. There are never any specific requirements regarding the choice of the survey method, but the characteristics of the information to be provided or the modality of collection are provided that seems to be very close to those offered by the modern methods of Geomatics. Among the preliminary ones, regarding the approach strategy, there are the adoption of analysis systems that are part of the territorial context and reach the detailed description of the individual structural elements only where necessary. In this context, innovative photogrammetric methods can be made flexible by the need to generate multiscale models that provide a significant framework, for example by using the UAV photogrammetry, and in-depth analysis of areas or parts of buildings or their parts, through higher resolution and accurate models.

The progressive information deepening or the stratification of the levels of knowledge referred to in these regulatory documents are high responsive to the adoption of the typical reference system for all collected data using geomatics methods and the ability to capture and record large data bases, allowing for deferred analysis in time. Extremely important in risk or damage assessment contexts is the ability to provide accurate and rich documentation such as photogrammetric (both aerial and terrestrial), characterized by low cost and cost-effective. Just as the high level of processing automation (orthophoto production, surface analysis, etc.) enable to configure the maximum sustainability in terms of resource consumption today. Geomatics makes more and more approachable new focused data recording methods based on multisensor approach, semi-automatic processing tools and various documentation outcomes featured by high detailed information and verified accuracy as high scale textured 3D models, orthoimages and Digital Surface Models (DSM). 3D surface reconstruction are nowadays efficiently achieved by digital Structure-from-Motion (SfM) photogrammetry based on image-matching algorithms, as it is now well known in literature; this can be applicable today to all types of cameras, up to the commercial ones. Those models can be textured by metrically restrained images with very-high quality and this improves the potentialities of complex structures analysis, representation and communication to the public of users in the field of conservation, diagnosis and restoration.

\subsection{D models and 2D/3D representation for material diagnosis and decay assessment}

For architectural and archaeological documentation and restoration purposes, the metric products derived from very high scale models as orthoimages are useful at different scales, to set up drawings and interpretation of constructive elements and material and to represent and communicate different types of information (colours, materials, damages, deterioration...). Specifically about the ancient structures and masonries documentation, the chance of detailed orthoimages projection and surfaces unrolling development offers many opportunities. Users obviously find many difficulties in the measure of phenomena on a curved surface, so the ability to measure for example the effects of damage on measurable surfaces, that is, transformed or developed on a plane, is quite attractive for those who are not specialized in measurements. The advantages are many: to use it as a complete database of qualitative and quantitative information in frequently diffuse metric digitization which are, as well known, pathologies mapping, damages as collapses and cracking identifying, stratigraphic analysis, statistical areas-based inquiries, restoration intervention and so on. In recent years, many studies experienced applications and ad hoc solution for digital documentation systems based on GIS use for 2D-3D knowledge organization in spatial database, for example with the management of orthoimages and Digital Elevation Models for surface analysis of metric and radiometric georeferenced data (Cerutti et al., 2015; Donadio \& Spanò, 2015).

\subsubsection{Orthoproiection and 3D development of curved surfaces}

The availability of high-definition digital models with high accuracy and the possibility to manage them in the three spatial dimensions allows being able to handle the complex shapes and their generating basic geometries. Consequently is quite easy to give a graphical restitution particularly for complex objects, as those belonging to the Architectural Heritage, often characterized by the presence of curved surfaces (Macher et al., 2015).

Cylindrical, conical, spherical, parabolic or ellipsoidal surfaces are typical of architecture documentation matters, for common architectural elements as cupolas, domes, vaults, ceilings, columns, towers, belfry (Macher et al., 2015; Theodoropoulou et al., 2001; Karras et al., 1997). Many strategies can be useful for orthoimages generation (Hemmleb \& Wiedemann, 1997), firs of all distinguishing between a single-image approach and a multi-image context, by bundle adjustment (Theodoropoulou et al., 2001). If a plane surface is considered, a projective rectification is need to be performed: it consists in omographic parameters determination, according to the relation between the mean image plane and the projective plane. Differently from common ortoprojection of plane surfaces, architectural curved surface, and as such often irregular and unique, present many challenge, firstly in the initial phase of interpretation of the shape. In case of curved surface, we talk about the development of a 3D surface by unrolling the 3D shape maintaining the geometric information metrically controlled in its accuracy. It is necessary to make it possible to assimilate the object or the surface to the basic geometric primitive, curves or volumes, through a segmentation process by cut section and profiles production, or by fitting algorithms applied on point clouds detecting the best adaptive shape according to point cloud curvature distribution and density. Once recognized the shape, the assumption of a specific surface type allows the corresponding equation to be directly employed (Theodoropoulou et al., 2001). The unwrap process is based on a parametric approach of rectification: we need to describe the parameters of the object surface (cylinder or cone) with the help of control points. The height values and the angles of the developable area are given and the origin coordinates of cylinder and radius are calculated. (Hemmleb \& Wiedemann, 1997).

For an operational point of view, nowadays, different strategies can be followed for a practice of development to produce an orthoimage of a conic shape. In (Markiewicz et al, 2017; Bevilacqua et al., 2016; Tortosa Garcia et al, 2016; Marinov, 2008; Lerma \& Tortosa, 2004) some example of experimental workflow are deeply displayed. Commercial software 3DReshaper (http://www.3dreshaper.com/) and open-source Cloud Compare (http://www.danielgm.net/cc) offers some effective tools to calculate cylindrical and conical projection. For the first one, a cylindrical 2D unrolling of the 3D mesh surface is performed, based on the principal axis detection and the mean radius manual or automatic setting. In the second case, for CC, the unrolling is related to point clouds. Thanks to the RANSAC Shape Detection algorithm processing, the main values for the geometrical definition of cones or cylinders are extracted. Then, after the setting of axis direction and radius (for cylinders) and the setting of axis direction, radius, cone angle and apex (for cones), a $2 \mathrm{D}$ unrolling of the $3 \mathrm{D}$ point cloud can be carried out. 


\section{A RURAL DOVECOTE TOWER}

The paper focused now on a comparative study carried out on a late-medieval stratified dovecote tower in Verolengo (Torino) with a particular trunk-conical shape, which had been intended to provide observations about analysing and reconstructing an identity and a stratified history and architectural connotation, de facto not recognized yet (Figure 1). The comparison with architectural structures made up of analogous territorial, formal and constructive characterization, with the interpretation of historical maps representations and cadastre, contribute to finalize an historical definition about the building (Viglino Davico et al., 2010; Comba et al., 2007; Viglino Davico et al., 2007). This tower, in fact, is contextualized in the landscape of rural settlements, such as isolated towers, fortified farmhouse, typical of the Piedmontese rural territory of the 13th-17th centuries and, in particular, the Marquisate of Monferrato landscape. With a careful observation of the architectural structure with the geometric modelling from the photogrammetric 3D survey, the building's peculiarities emerged, together with its original potential shape and its different layers. In fact, all this above lets to a careful interpretation of the architectonical and constructive elements and materials characterization and condition according to the legible constructive stratification, and it allowed an interpretation and a possible definition of the conceivable 'history' of the building. (Sammartano, 2010). The tower in Verolengo is isolated in the countryside, in moderately good condition; from consulted documentary sources, it does not seem bringing any information about its origin and evolution. The structure has a circular plan, $5 \mathrm{~m}$ diameter and it is developed with an approximately cylindrical shape (after the 3D survey a particular trunk-conical shape was defined); the height of the whole tower above the top of the roof is about $18 \mathrm{~m}$. The tower is connected to a wall that once surrounded a land pertaining the old fortified farmhouse that was reasonably standing in front of the tower; the curtain of the first 5 levels in mixed stone and brick embedded in mortar, brick punctuated by appeals clay. The dovecote is brick tile and special shapes (Figure $1)$. The cover consists of a truss in wood and brick tiles.

The importance of the 3D vector from the topographic survey (Figure 2), together with the successive 3D photogrammetric model, closely connected to the dense radiometric information, will be particularly expressed in two main direction for the diagnosis both of volumetric assessment of the structure and the material characterization of the walls with mixed masonries.

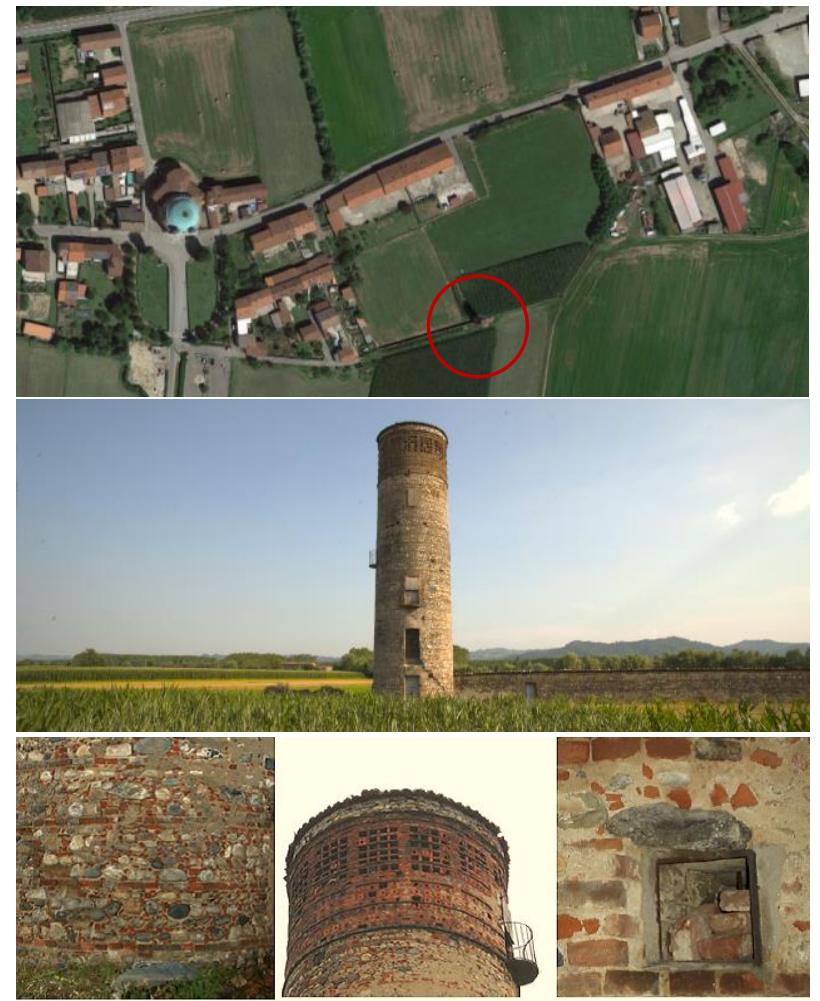

Figure 1. The late-medieval tower. Satellite image by Google $\odot$. Details on the dovecot and on mixed stone and brick masonry.

Figure 2. (Below) (a) The North and the East side of the tower; (right) the N-S section; (b) Representation of some of the tower plans: (from left) ground floor; second floor; dovecot level; circular roof structure. (Original scale 1:50)

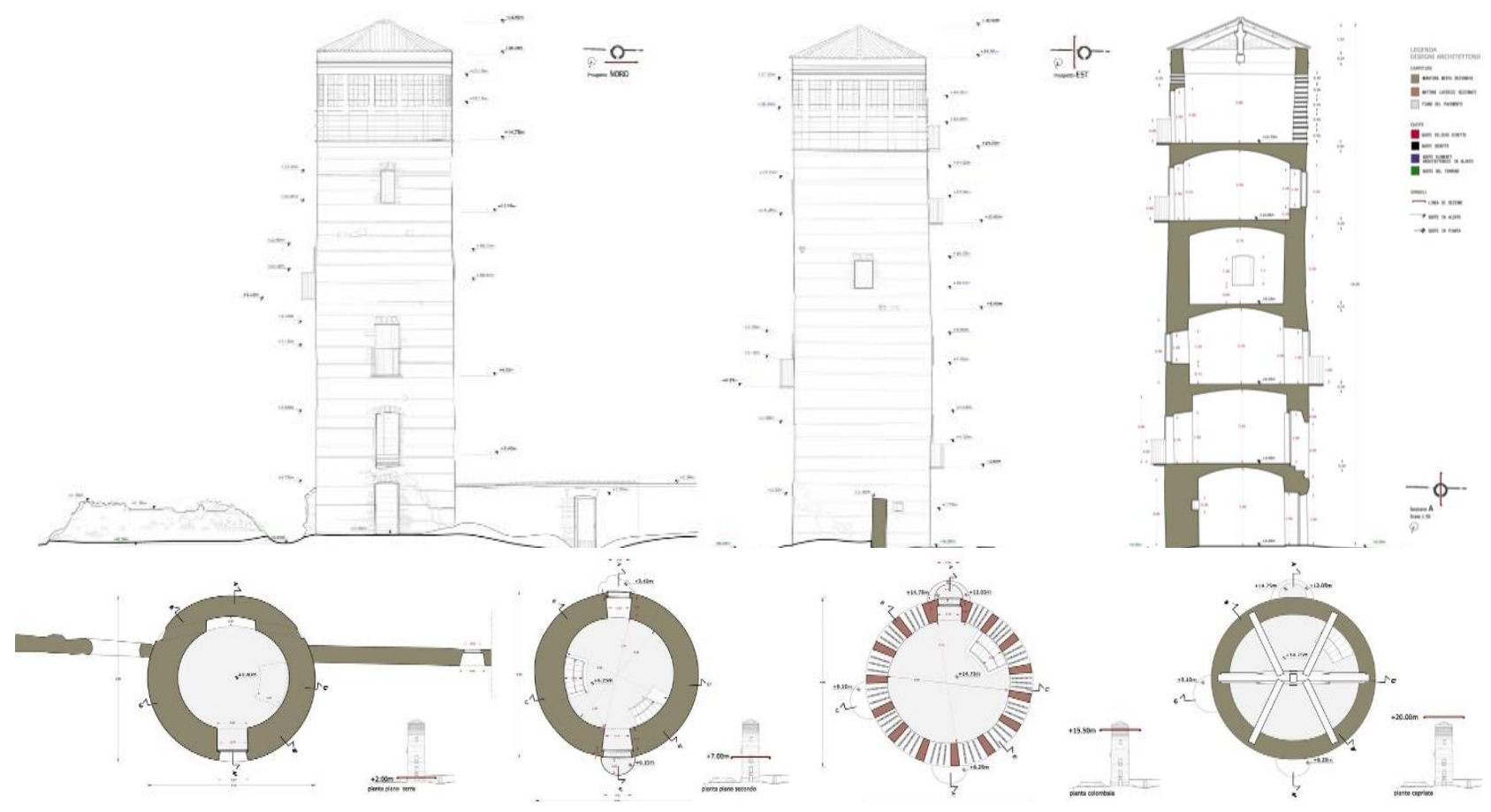




\subsection{The 3D metric survey with traditional approach}

In year 2010 a traditional metric survey have been carried out with the planning of a topographic network of five vertex linked around the building and surrounding wall depending from accessibility condition. From these vertex an abundant set of points were measured on the building and on the masonries of the sidewalls, in order to define many types of information: the volume definition, through of the cylinder generatrixes and directrixes, and the definition of the architectural elements (masonry openings such as doors, windows, slots, holes or constructive punctures), frames, architectural details on the structure and the dovecote. Furthermore, a photogrammetric ortoprojection on the base of a set of measured control points was applied for the study of lateral boundary walls and direct metric survey was performed on the indoor parts of the tower.

The final reflections resulting from the study of collected metric data led to the formulation of some interpretative hypotheses. The material analysis and constructive geometric anomalies made an important contribution to the definition of the state of construction at the time as well as the various and subsequent stratifications. First of all, for the volume assessment, a sensible slant of the central axe was detected thanks to the managing and measurement of the progressive horizontal cut sections on the tower volume and the evaluation about the trend of the section centres along the height dimension (Figure 3). A reflection came up with both the origin and cause of the deformation, which is if the lateral deflection was originated during the construction for a defect due to the time's workers, or instead if it was not caused by a slight structural subsidence. Later, with the careful observation of the structure modification on the curtain for the openings and the dovecot volume insert, and the historicalarchitectural context of reference, emerged the peculiarities of the building and its possible original conformation.
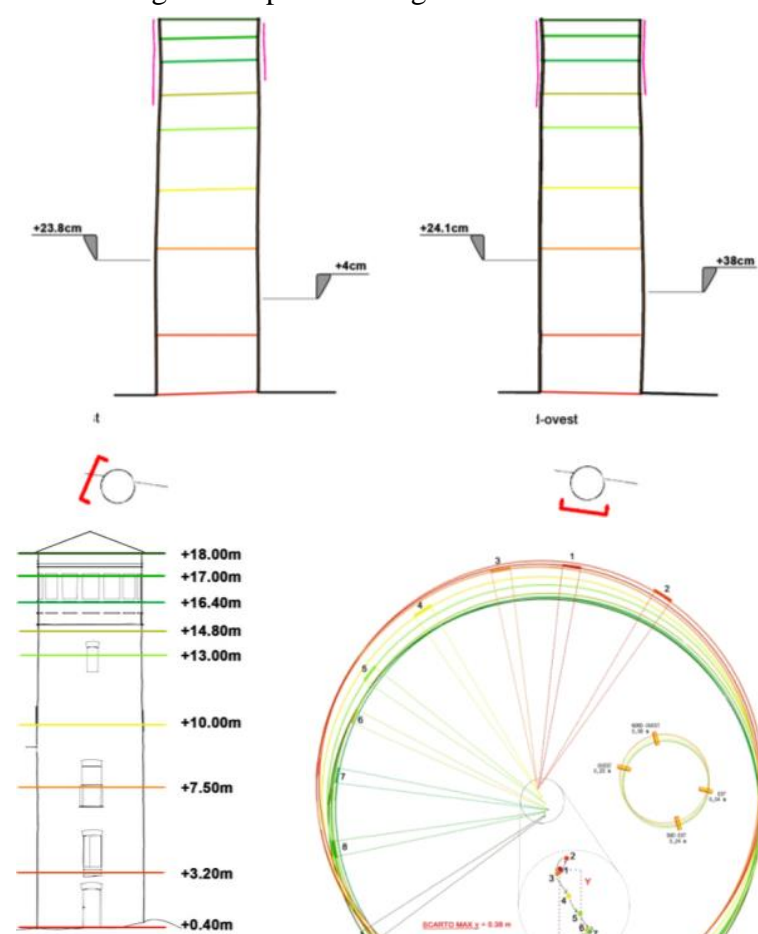

(1)

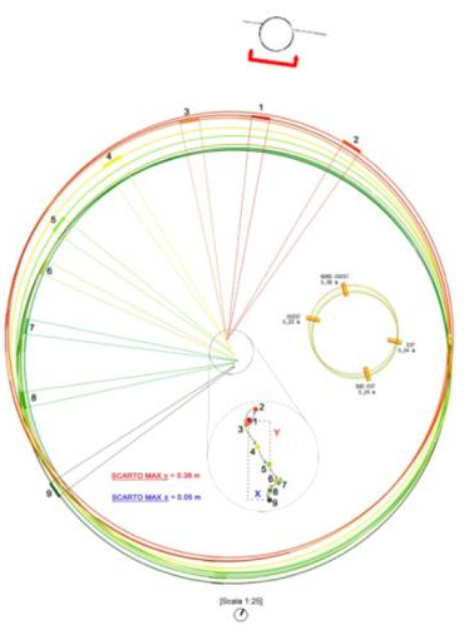

Figure 3. Study of the vertical axe of the tower, and progressive displacement of the cone progressive sections, which have been assumed to date from the construction phase.

\subsection{The 3D digital approach for 3D reconstruction and high detail modelling}

The topographic survey just described, effective for allowing the building interpretation, its plausible dating and volumetric irregularities attributable to the design phase, has certainly resulted in very long processing and careful study of the significant sections outlined through the detailed survey performed by total station. It was therefore useful carry out a three-dimensional modelling using dense image-matching photogrammetric software, by means of a SfM algorithm to achieve dense clouds and triangulated models. In order to evaluate the results that we will see in favour of the use of this technology, it must be taken into account that the topographic control points of the first experience were used. Even though this detail is not secondary, productivity and timescales compared to the information skills are entirely for the benefit of the most modern techniques. It was planned to acquire images with a high overlap (about 90\%), according to about 32 radial direction around the tower, employing two different shooting distances so that a farthest image resumes overlap at least two images at a distance of Minor resumption. The employed sensor is the Canon EOS-1Ds Mark II with a pixel size of $7.2 \times 7.2 \mu \mathrm{m}, 24 \times 36 \mathrm{~mm}$ sensor, and the optics used was $20 \mathrm{~mm}$ and $24-70 \mathrm{~mm}$ for a deep focus on the top dovecot (Table 1).

\begin{tabular}{c|ccc}
\multirow{2}{*}{} & \multicolumn{3}{|c}{ Dataset by Canon EOS-1Ds Mark II } \\
\cline { 2 - 4 } & Sensor & N$^{\circ}$ images & GSD \\
\hline (1) & $20 \mathrm{~mm}$ & 32 & $6.63 \mathrm{~mm} / \mathrm{pix}$ \\
$(2)$ & $70 \mathrm{~mm}$ & 30 & $2.53 \mathrm{~mm} / \mathrm{pix}$ \\
(3) & integration & 60 & $3.74 \mathrm{~mm} / \mathrm{pix}$
\end{tabular}

Table 1. The image datasets for the dovecot tower

These dataset were processed as usual for digital photogrammetric workflow based on SfM with image-matching algorithms, with orientation and tie points extraction, bundle block adjustment, densification and mesh triangulation with high definition RGB texturization (Figure 4).

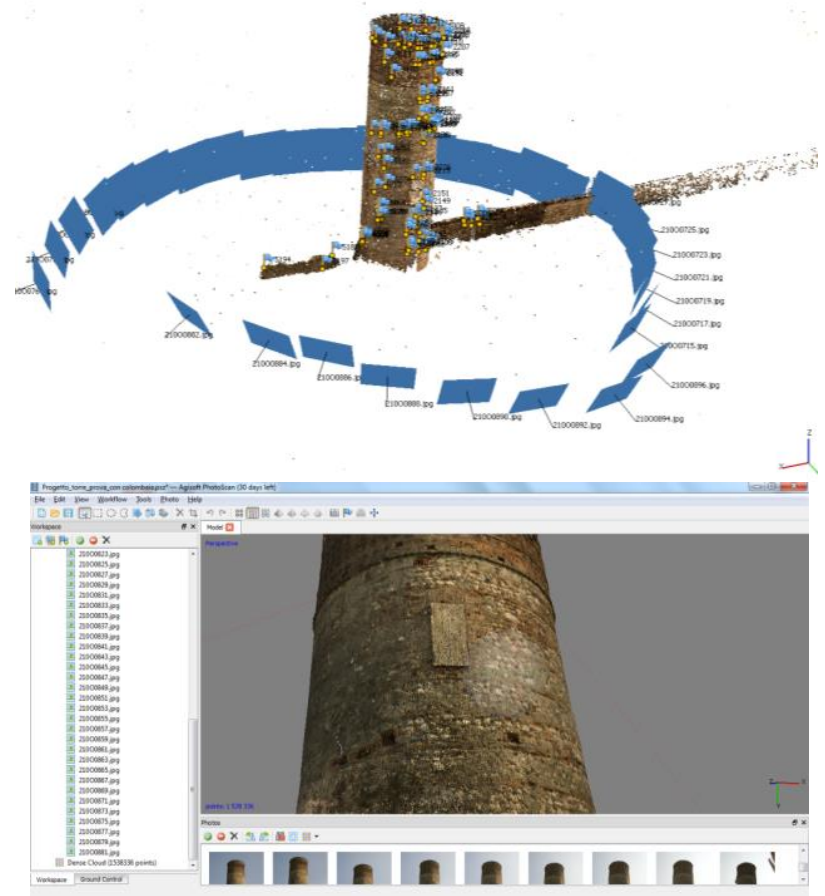

Figure 4. The position of image acquisition planning and estimated camera 3D position after orientation phase. 


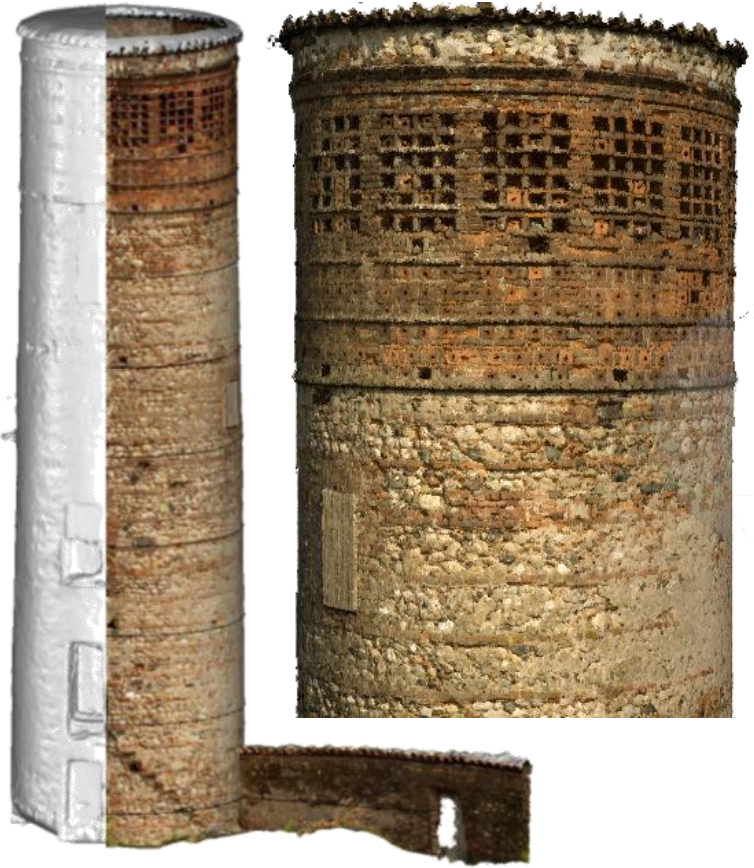

Figure 5. The 3D photogrammetric model and a zoomed image on the dense point cloud on the dovecot

\begin{tabular}{c|cccc|cccc} 
& \multicolumn{4}{|c|}{ GCPs $(\mathrm{cm})$} & \multicolumn{4}{c}{ CPs $(\mathrm{cm})$} \\
& $\mathrm{X}$ & $\mathrm{Y}$ & $\mathrm{Z}$ & Mean & $\mathrm{X}$ & $\mathrm{Y}$ & $\mathrm{Z}$ & Mean \\
\hline$(1)$ & 1.474 & 1.355 & 1.103 & 1.3107 & 2.185 & 2.460 & 0.920 & 1.8550 \\
$(2)$ & 0.894 & 0.642 & 0.719 & 0.7517 & 1.320 & 1.537 & 1.362 & 1.4063 \\
$(3)$ & 1.4049 & 1.337 & 0.975 & 1.2390 & 2.154 & 2.690 & 0.746 & 1.8633
\end{tabular}

Table 2. RMS error on Ground Control Points (GCPs) and Control Points (CPs)

The metric control of the $3 \mathrm{D}$ models is reported (Tab 2) and finally two different models are produced: the global one (1) with the complete tower volume, and the second one (2) focused on the dovecote particular structure, with the $70 \mathrm{~mm}$ set of images.

(1) 5,700,000 pts (dense cloud) and 1,100,000 (triangles)

(2) 2,200,000 pts (dense cloud) and 990,000 (triangles)

\subsection{Data comparison and volume assessment by $3 \mathrm{D}$ models}

For the volume analysis and definition finalized the evaluation and mapping of anomalies, as well as the confirmation of what emerged from geometry evaluation in traditional metric survey, the tower was approximated to the best fitting regular shape. A cylindrical and conical volume are calculated, and compared to the 3D mesh produced by photogrammetric approach. The numerical values for the definition of the cone and cylinder are listed below and showed in Figure 6. Additionally, a simplified 3D surface build up by interpolation from circular cut section of the detailed model was calculated and, in comparison with the original volume, demonstrate as expected, the best fitting.

\section{CYLINDER (A)}

- $\quad \mathrm{r}=2.417 \mathrm{~m}$

- Centre: $136.080,97.077,99.516$

- Normal axe: 0.002032, $-0.014572,0.999892$

\section{CONE (B)}

- $\mathrm{r}=2.371412 / \mathrm{R}=2.451233$

- Centre: $136.081,97.040,99.510$

- Angle: 0.258246

- $\quad$ Normal axe: 0.002045, $-0.011852,0.999928$
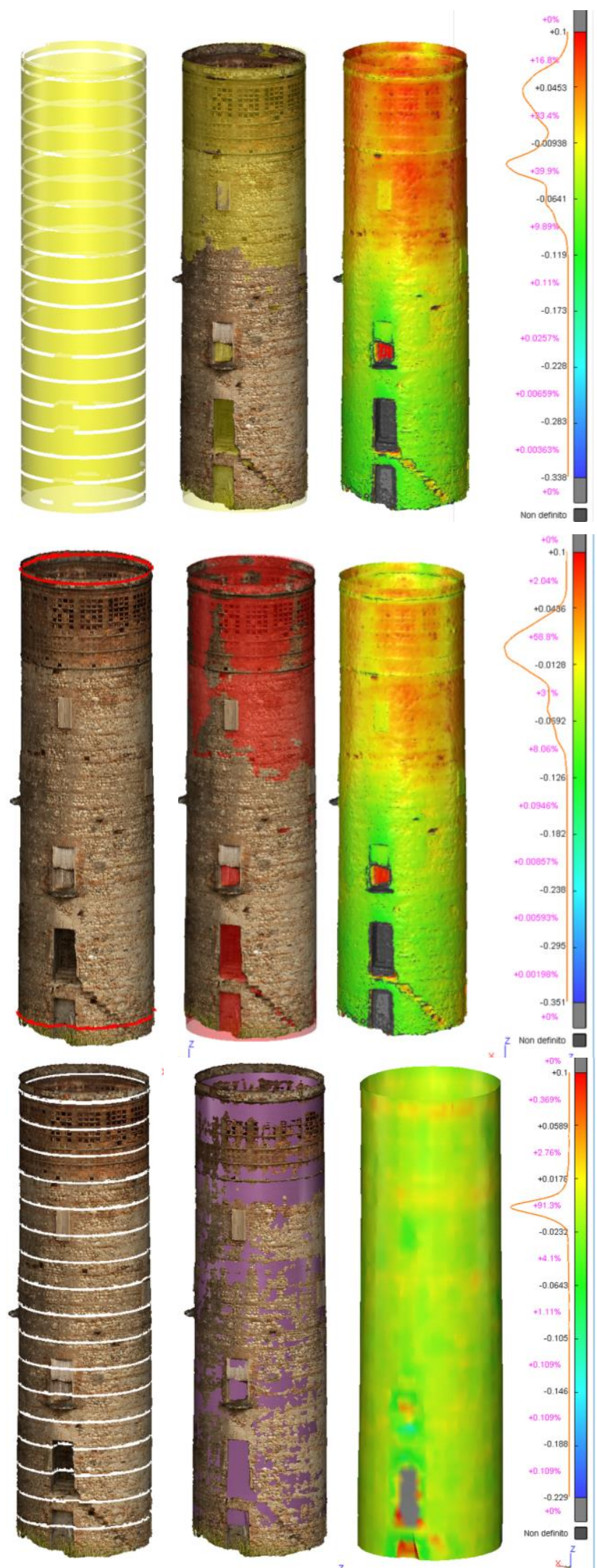

Figure 6. (A) 3D model analysis and approximation to a mean cylinder surface $(\mathrm{r}=2.417 \mathrm{~m})$; (B) 3D model analysis and approximation to a mean trunk-cone surface $(\mathrm{r}=2.371412$ / $\mathrm{R}=2.451233$ ); (C) 3D model analysis and approximation to a $3 \mathrm{D}$ mesh that better fit the structure deformation surface 


\begin{tabular}{l|l|cc}
\multicolumn{2}{l|}{} & \multicolumn{2}{c}{$\begin{array}{c}\text { Surface comparison error }(\mathbf{m}) \\
\text { Mean }\end{array}$} \\
\hline (A) & Cylinder & -0.00035 & 0.09931 \\
(B) & Cone & +0.00605 & 0.09595 \\
(C) & 3D mesh & -0.01755 & 0.11149
\end{tabular}

Table 3. The surface comparison error between the three solutions and the 3D triangulated model of the tower

In Table 3, the mean errors from the comparison between the 3D complex mesh and the geometrical surface chosen as reference for the possible surface unrolling according a cylindrical or conical development.

\subsubsection{The dovecote volume analysis and surface development}

A focus on the surface development was interesting to be carried out, now, on the dovecote volume (Dataset 2), after the production, segmentation and optimization of the point cloud and mesh. The metric product has a very high level of detail for geometrical definition and also for RGB texture (Figure 7). The cylindrical best fitting surface has been studied and then compared to the real dovecote surface.

It is possible to see in Figure 8, many irregularities and defamation of the surface trend compared to the regular cylindrical one.

\section{CYLINDER}

- $\mathrm{r}=2.386732$

- $\quad$ Centre: $136.114,96.859,113.493$

- $\quad$ Normal axe: 0.002961, $-0.010691,0.999938$

With the 3D Reshaper unrolling tools, starting from the geometrical values for the cylinder definition, an ortoprojection in very high detail of the developed surface was calculated (Figure 10, 11).
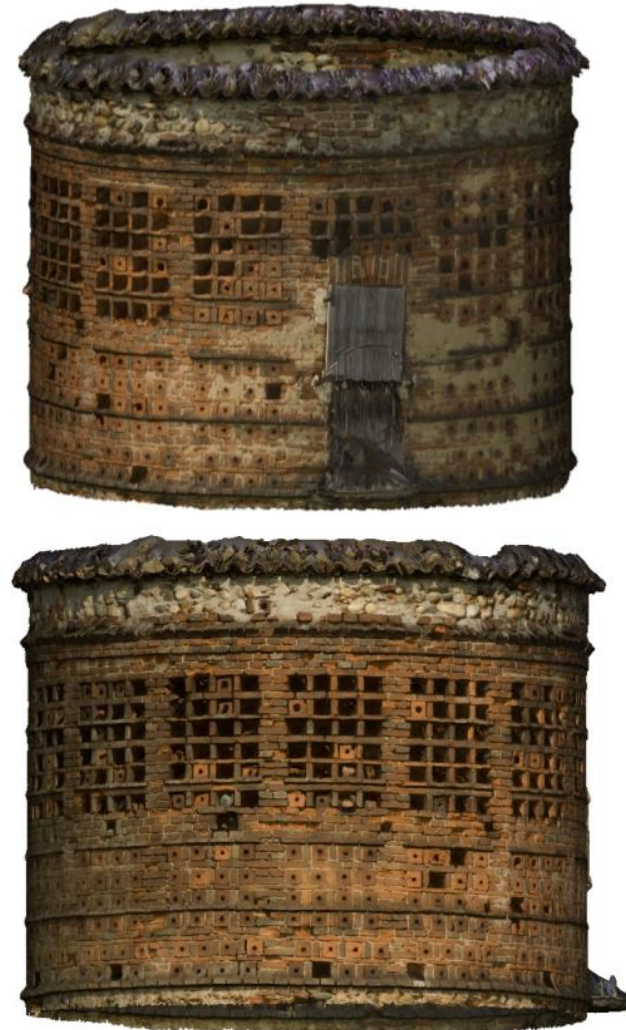

Figure 7. Very high detailed 3D textured model from a South view and a West view.
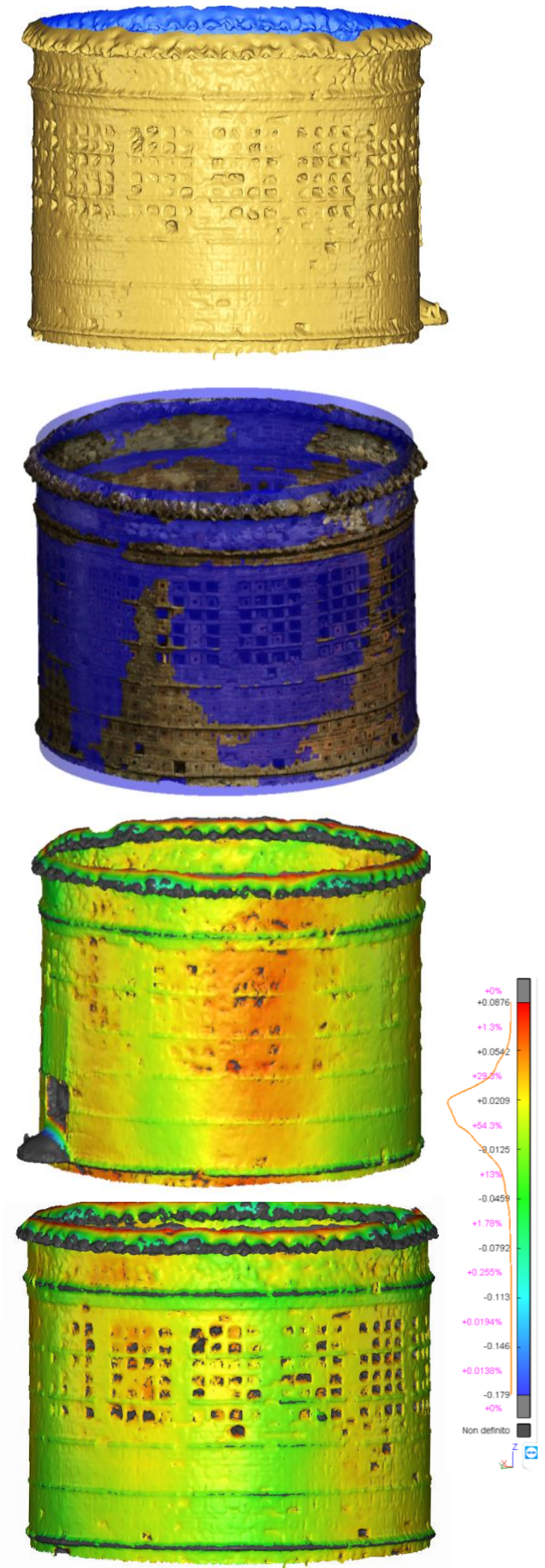

Figure 8. 3D mesh without RGB information; fitting to the cylindrical volume; 3D model analysis by surface comparison between the photogrammetric mesh and the best fitting cylinder. 
A set of assorted 3D measures well distributed on the dovecote volume were then extracted in order to have a statistical control of accuracy on the ortoprojection with developed surface. Measures projected on the triangulated mesh have been compared with the same measured on the digital ortoimage of the developer surface (Figure9). Results are listed in Table 4. As expected better results on vertical measures have to be related to horizontal measure that offer discrete results on the sides of unrolled area, and definitely on average, a good result, improvable with the use of better unrolling algorithms.

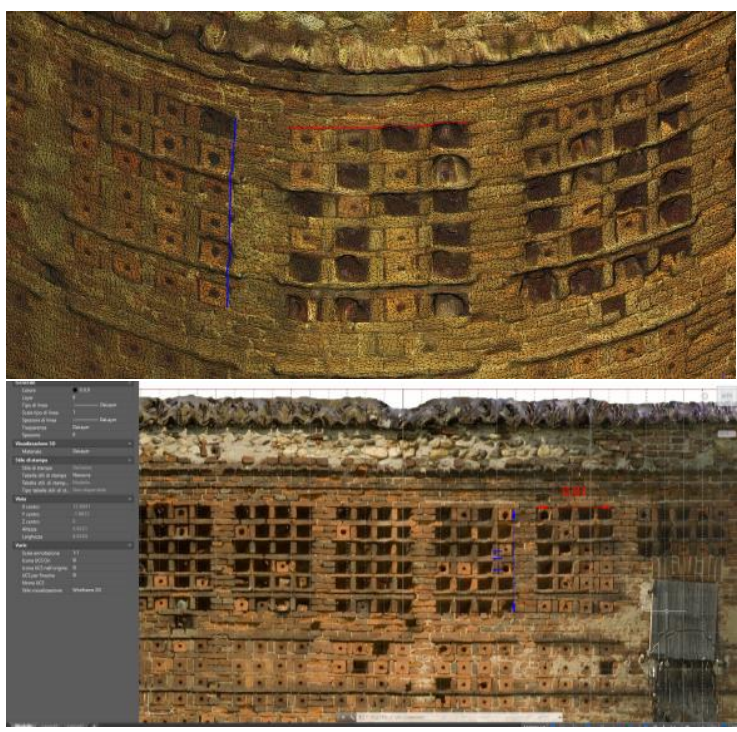

Figure 9. 3D model analysis

\begin{tabular}{|c|c|c|c|c|c|}
\hline \multicolumn{6}{|c|}{ Control measurement population (m) } \\
\hline & \multicolumn{4}{|c|}{ Horizontal } & Vertical \\
\hline & $\begin{array}{l}\text { Top } \\
\text { part }\end{array}$ & $\begin{array}{l}\text { Middle } \\
\text { part }\end{array}$ & $\begin{array}{r}\text { Lower } \\
\text { part }\end{array}$ & TOT & TOT \\
\hline Mean & 0.07732 & 0.00753 & 0.07577 & 0.0538 & 0.00295 \\
\hline St.dev. & 0.05632 & 0.00019 & 0.00197 & 0.0745 & 0.00002 \\
\hline
\end{tabular}

Table 4. A population of measurements for unroll control between 3D model and developed surface.

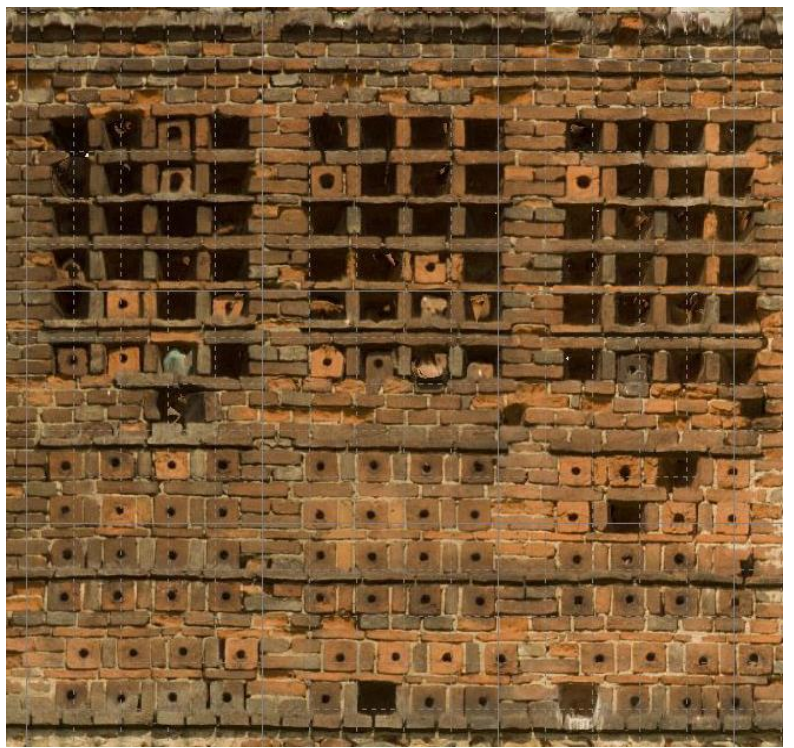

Figure 11. Zoomed view of the dovecote on high detail texture
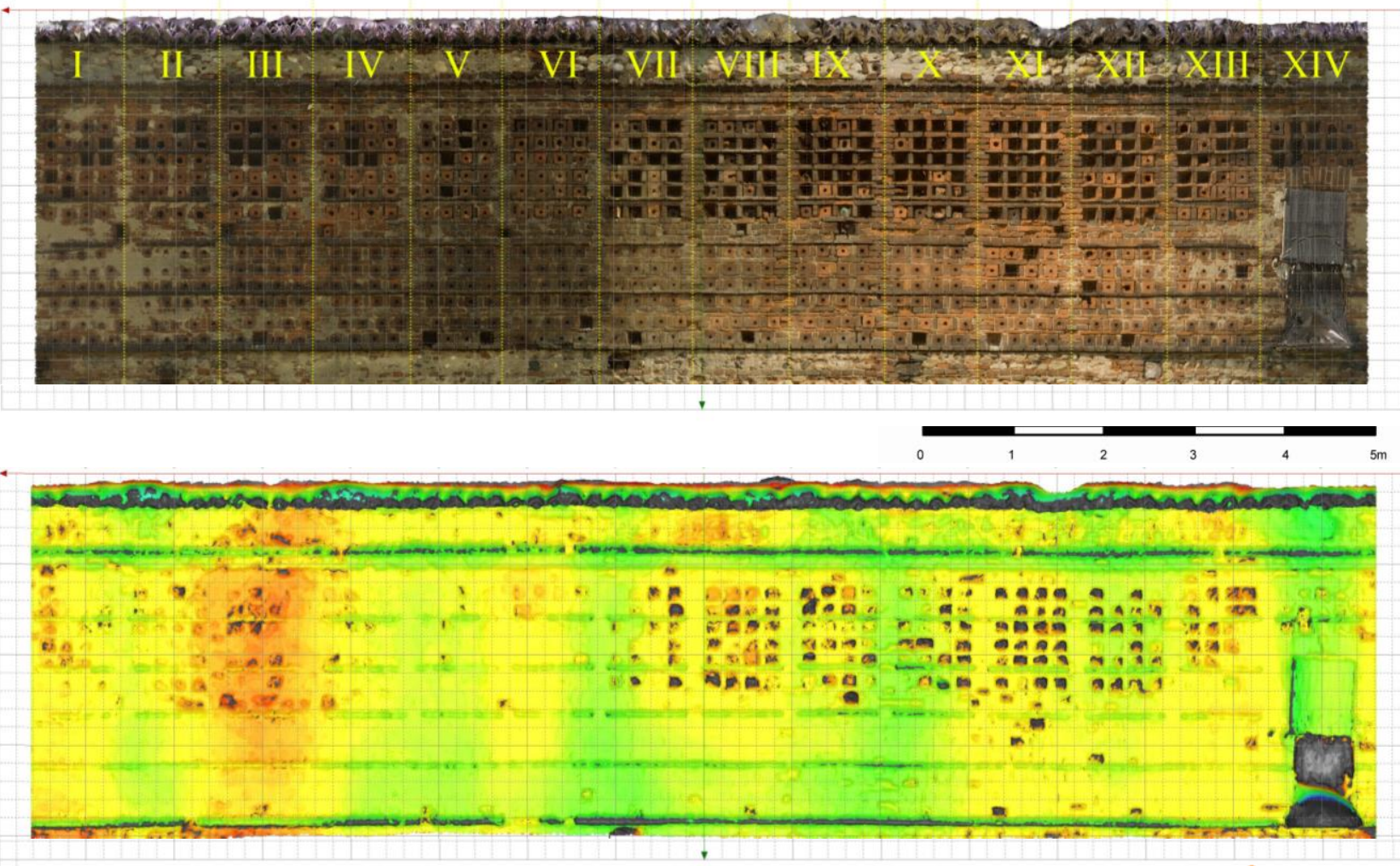

Figure 10. The results of the $2 \mathrm{D}$ unrolled surface of the dovecote, where are pinpointed the characteristic quadrants with particular square holed bricks. Next, the 2D unrolled surface of the 3D model analysis by surface comparison between the photogrammetric mesh and the best fitting cylinder 


\section{CONCLUSION}

In order to practice a more sustainable approach in the general process of Cultural Heritage preservation and protection, digital tools provided by Geomatics allows having a more comprehensive and complex range of useful graphical products available for multipurpose approaches, depending on the predefined objectives of the metric survey. In the specific issues of the material analysis, pathologies mapping and structural assessment, especially in risk or damage contexts for complex Archaeological and Architectural objects, the improved descriptive capabilities of 3D digital photogrammetry have a key role. In fact, for the geometrical definition of both individual structural elements as well as for the whole volumes behaviour, the multi-scale and multi-temporal attribute of photogrammetric close-range approach (both aerial and terrestrial), offers as a valid response, a very high detailed and cost-effective results.

\section{ACKNOWLEDGMENT}

Authors would like to kindly thanks Arch. Giacomo Patrucco for his help in data processing.

\section{REFERENCES}

"Valutazione e riduzione del rischio sismico del patrimonio culturale con riferimento alle Norme Tecniche per le Costruzioni di cui al Decreto del Ministero delle infrastrutture e dei trasporti del 14/01/2008". Direttiva del Presidente del Consiglio dei Ministri, Gazzetta Ufficiale n.47 del 26 febbraio 2011 - Supplemento ordinario n.54.

Apollonio, F. I., Gaiani, M., Basilissi, W., and Rivaroli, L., 2017. Photogrammetry driven tools to support the restoration of open-air bronze surfaces of sculptures: an integrated solution starting from the experience of the Neptune Fountain in Bologna, Int. Arch. Photogramm. Remote Sens. Spatial Inf. Sci., XLII-2/W3, 47-54, doi:10.5194/isprs-archives-XLII-2W3-47-2017, 2017.

Bastonero, P.; Chiabrando, F.; Donadio, E.; Spanò, A. 2014. Fusion of 3D models derived from TLS and image-based techniques for $\mathrm{CH}$ enhanced documentation, ISPRS Annals of The Photogrammetry, Remote Sensing And Spatial Information Sciences, II-5, DOI: 10.5194

Bevilacqua, M.G.; Caroti, G.; Martínez-Espejo Zaragoza, I.; Piemonte, A., 2016. Frescoed Vaults: Accuracy Controlled Simplified Methodology for Planar Development of Three-Dimensional Textured Models. Remote Sens. 2016, 8, 239.

Cerutti, E.; Donadio, E.; Noardo, F.; Spanò, A., 2015 Strategies for data storing in CH conservation plans. Façades analyses in GIS environment. In: Heritage and landscape as human values. Conference proceedings. Edizioni Scientifiche Italiane spa, pp. 533-539. ISBN 9788849530575

Chiabrando, F.; Sammartano, G.; Spanò, A., 2017. A comparison among different optimization levels in 3D multi-sensor models. A test case in emergency context: 2016 Italian earthquake. In: International Archives Of The Photogrammetry, Remote Sensing And Spatial Information Sciences, vol. XLII-2/W3, pp. 155-162.

Comba, R.; Panero, F.; Pinto, G. (a cura di), 2007. Motte, torri e casseforti nelle campagne medievali (secoli XII-XV), atti del convegno (Cherasco, 2325/09/2005), CISIM Cherasco.

Donadio, E.; Spanò, A., 2015. Data Collection and Management for Stratigraphic Analysis of Upstanding Structures. In: GISTAM 2015 Geographical Information Systems Theory, Applications and Management, Barcelona, 28-30 April 2015. pp. 34-39

Hemmleb, M., Wiedemann, A., 1997. Digital rectification and generation of orthoimages in architectural photogrammetry. In:
International Archives of Photogrammetry and R emote Sensing, Vol. XXXII, Part 5C1B, pp. 261-267

Karras, G., Patias, P., Petsa, E., Ketipis, K., 1997. Raster projection and development of curved surfaces. In: The International Archives of Photogrammetry and Remote Sensing, Vol. XXXII, Part 5C1B, pp. 179185.

Lerma, J. L., Seguí, A. E., Cabrelles, M., Haddad, N., Navarro, S., Akasheh, T., 2011. Integration of laser scanning and imagery for photorealistic $3 D$ architectural documentation. INTECH Open Access Publisher. DOI: 10.5772/14534

Lerma, J.L., Tortosa, R.V., 2004. Digital development of a small Valencian tower. Int. Arch. Photogramm. Remote Sens. Spat. Inf. Sci. 2004, 35, 451454.

Macher, H. Grussenmeyer, P.; Kraemer, C.; Guillemin, S. 2015. Overview of $3 D$ documentation data and tools available for archaeological researches: case study of the Romanesque church of Dugny-sur-Meuse (France), The International Archives of the Photogrammetry, Remote Sensing and Spatial Information Sciences, Volume XL-5/W7, 2015. 25th International CIPA Symposium, 3/08-04/092015, Taipei, Taiwan

Marinov, B. D. (2008). Hierarchical modelling and processing of space objects in architectural photogrammetry, Int. Arch. Photogramm. Remote Sens. Spatial Inf. Sci., ol. XXXVII. Part B5. Beijing, 2008

Markiewicz, J., Zawieska, D., and Podlasiak, P. (2017). Comparing multisource photogrammetric data during the examination of verticality in a monumental tower, Int. Arch. Photogramm. Remote Sens. Spatial Inf. Sci., XLII-2/W3, 475-480, doi:10.5194/isprs-archives-XLII-2-W3-475-2017

Ortiz-Cordero, R.; Hidalgo Fernández, R. E., 2017. 3D Photogrammetry, capacity, filling time and water flow simulation of Cordoba's MosqueCathedral Islamic cistern, Digital Applications in Archaeology and Cultural Heritage, Volume 4, March 2017, Pages 39-48, ISSN 2212-0548, http://doi.org/10.1016/j.daach.2017.02.003.

Sammartano, G.; 2011. Una torre a Verolengo. Spunti di osservazione per la definizione di un 'identità. I contributi del rilievo metrico-architettonico e dell 'indagine storica per lo studio dei beni culturali, Master Thesis, tutors. A. Spanò, A. Longhi, P. Davico, 2011.

Spanò, A; Vizzini, C., 2016. Modelli fotogrammetrici per la descrizione dei dissesti delle strutture. In: Hierapolis Di Frigia VIII 1-2 Le Attivita delle Campagne di Scavo Restauro 2007-2011 (2 Vols.) / D'Andria, Francesco, Caggia, Maria Piera, Ismaelli, Tommaso. Ege Yayinlari, Istanbul, pp. $57-$ 62. ISBN 9786059680127

Theodoropoulou, I., Petsa, E., Karras, G. E., 2001. Digital Surface Development of Large Cylindrical and Conical Structures With a Single Image Technique. The Photogrammetric Record, 17(97), pp. 25-37.

Tortosa Garcia, R.; J.Blasco i Senabre, O. Aparicio González, L. Gimeno Martínez, A. Vilaplana Sellés, J. Menchón i Bes, 2016. Development of three-dimensional models of conical aspect: la Torre Vallferosa Torà, In: 8th International Congress on Archaeology, Computer Graphics, Cultural Heritage and Innovation 'ARQUEOLÓGICA 2.0', Valencia (Spain), Sept. $5-7,2016$.

Viglino Davico, M.; A. Bruno JR, E. Lusso, G. G. Massara, F. Novelli, (a cura di), Atlante castellano, strutture fortificate della provincia di Cuneo, Torino 2010.

Viglino Davico, M.; A. Bruno JR, E. Lusso, G. G. Massara, F. Novelli, (a cura di), Atlante castellano, strutture fortificate della provincia di Torino, Torino 2007

Voulodimos A, Doulamis N, Fritsch D, Makantasis K, Doulamis A, Klein M., 2016. Four-dimensional reconstruction of cultural heritage sites based on photogrammetry and clustering. J. Electron. Imaging. 0001;26(1):011013. doi:10.1117/1.JEI.26.1.011013. 